\title{
Does substance use by family members and community affect the substance use among adolescent boys? Evidence from UDAYA study, India
}

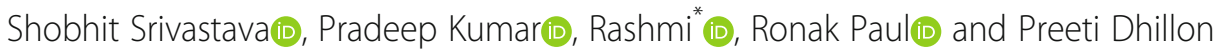

\begin{abstract}
Background: Substance use among adolescents is risky behavior that had emerged as a concern in both developed and developing countries. Evidence revealed that substance use is more frequent among those adolescents whose immediate family members (parents, siblings and grandparents) also indulge in such consumption; however, scarce literature is present in the Indian context. Therefore, the present study examined whether substance use among family members and in the community is associated with the substance use behavior of adolescent boys in Uttar Pradesh and Bihar.
\end{abstract}

Method: We used the data for 5969 adolescent boys aged 10-19years from the Understanding the Lives of Adolescents and Young Adults (UDAYA) survey conducted in 2016. A three-level random intercept logit model was utilized to understand the association of adolescent substance use behavior with familial and community context.

Results: We found that $16 \%$ of adolescent boys were using any substance (tobacco or alcohol or drug). The substance use was significantly higher among adolescent boys who were school dropouts (40\%) than those who were currently in school. The prevalence of substance use is also high among those who were working (35\%). Moreover, 19, 24 and 28\% of the adolescents come from families where at least one of the family members consumed tobacco, alcohol and drugs, respectively. The odds of substance use were 2.13 times [Cl:1.44-3.17] higher among those adolescent boys whose family members also indulged in substance use. Moreover, the likelihood of substance use was 1.24 times [Cl:1.01-1.68] higher among the adolescent boys who come from a community with high substance use. Additionally, the risk of substance use is more likely among adolescent boys belonging to the same household of the same community.

Conclusion: It is evident that exposure to substance use in the family and community increases the likelihood of substance use among adolescent boys. There is a need for household- and community-level programmatic interventions to alleviate the risk of substance use among adolescents.

Keywords: Substance addiction, Tobacco and alcohol consumption, Family members, Adolescent boys, Community, Multilevel analysis, UDAYA

\footnotetext{
* Correspondence: rashmir635@gmail.com

International Institute for Population Sciences, Mumbai, Maharashtra 400088, India
}

C C The Author(s). 2021 Open Access This article is licensed under a Creative Commons Attribution 4.0 International License, which permits use, sharing, adaptation, distribution and reproduction in any medium or format, as long as you give appropriate credit to the original author(s) and the source, provide a link to the Creative Commons licence, and indicate if changes were made. The images or other third party material in this article are included in the article's Creative Commons licence, unless indicated otherwise in a credit line to the material. If material is not included in the article's Creative Commons licence and your intended use is not permitted by statutory regulation or exceeds the permitted use, you will need to obtain permission directly from the copyright holder. To view a copy of this licence, visit http://creativecommons.org/licenses/by/4.0/ The Creative Commons Public Domain Dedication waiver (http://creativecommons.org/publicdomain/zero/1.0/) applies to the data made available in this article, unless otherwise stated in a credit line to the data. 


\section{Introduction}

The adolescent phase involves exploring with new things along with an experience of physical, social, emotional and mental changes [1]. However, with the growing magnitude of responsibilities, experiences and competition among adolescents, the issue of risky behavior that affects the health of adolescents has received immense attention [2]. Substance use among adolescents is one such risky behavior that had emerged as a global concern $[3,4]$. Substance use is defined as the use of harmful mood-altering substances like alcohol, illicit drugs, tobacco and others. Substance use turns health-abusive when taken at the repeated course, leading to deleterious health issues and impairments with the capacity to affect the body physically, mentally and socially [5]. Globally, the consumption of alcohol was alone attributable to more than 3 million deaths [6]. Of this alcohol consumption-related death burden, India contributes a larger portion of 273,000 preventable deaths [7].

According to the report "Magnitude of substance use in India", the use of harmful substances like opioids, inhalants, sedatives, injected drugs, and alcohol had increased at an alarming rate, especially among adult Indian men [8]. In India, consumption of tobacco and alcohol has become common among adolescents, and in the case of tobacco consumption, the age of initiation was observed to be as low as 12 years [9]. Smokeless tobacco usages have also become very popular in India owing to its easy availability and inexpensive price [10]. Moreover, the use of both smokeless and smoked tobacco, alcohol and cannabis (a psychoactive drug) is widely prevalent among the adolescents residing in the Indian slums [11]. Existing studies had linked the substance usage among adolescents with age [12], education [13], poverty [14], migration and occupation exploitation [15], creating cool image among peers [16], working status [17], drug culture [18], socioeconomic correlates [19]. Moreover, substance use among the family members has also emerged to be an important predictor of substance use among adolescents in both developed and developing countries [20,21].

Studies have revealed that substance use is more frequent among those adolescents whose immediate family members (parents, siblings and grandparents) also indulge in such consumption [22, 23]. Existing research had further shown that generational continuity [24] and perception of drinking in the family was associated with excessive drinking behavior in adolescents [25]. A systematic review of 58 research papers had indicated that smoking use among family members makes adolescents more likely to indulge in smoking behavior [20]. Further, a study had shown that substance use by older siblings increases the likelihood of substance use among younger siblings [26]. Extant research has also shown that adolescent substance use has long-term consequences in the form of deteriorating health status, exhibiting violent behavior, proneness to accidents, loss of employment, a dropout from formal education, poor performance in education and career development, among the people of both developed [3, 27] and developing nations [28, 29].

Minimal research in India had come forward showing the effect of substance use among family members on adolescent substance use behavior. Despite having an awareness of the behavior-inducing effect of familial substance use on adolescents and the damaging consequences of such behavior, there is very limited research regarding the same in the Indian context. A single study had documented the initiation of tobacco use among those adolescents whose immediate family members (parents, grandparents or siblings) were already into it [30]. Besides the family effect, a couple of studies had also pointed towards the importance of community in adolescent substance use behavior [31, 32]. A multilevel study from United States Midwestern countries shows the influence of parents, communities, schools and peers on adolescent substance use behavior [33]. Moreover, a study from Northeast India had shown the role of community-related characteristics behind the increment of tobacco consumption among the whole population [34]. It was observed in these studies that consumption behavior varies with community culture, and thus, the role of the community behind an individual's behavior cannot be denied.

This brings the necessity to explore how the use of tobacco, alcohol, drugs and other substances among the family members affect the adolescent's substance use, taking into consideration the community factors. Different Indian studies have shown that the use of tobacco, alcohol and drugs was higher among adolescents [35-37]. In spite of such research, two relatively backward big Indian states (i.e., Uttar Pradesh and Bihar) lack the knowledge due to sparse public health data. A study by the National Drug Dependence Treatment Centre (NDDT C) had stated the vulnerability of adolescents in Uttar Pradesh towards the consumption of harmful substances [38]. Further, evidence reveals that boys were a highly vulnerable group among adolescents, but scarce literature shows that such vulnerability is due to familial and community contexts. This brings the point of departure for the present study. Using data from the Understanding the Lives of Adolescents and Young Adults (UDAYA) survey, this study examined whether substance use among family members and in the community is associated with the substance use behavior of adolescent boys in Uttar Pradesh and Bihar. From the methodological point of view, a three-level random intercept logit model is used to capture the effect of all individual, household and community factors on the substance use behavior of adolescent boys. 


\section{Data, variables and methods Data}

Secondary data analysis was performed on a crosssectional dataset obtained from the Understanding the Lives of Adolescents and Young Adults (UDAYA) survey [39]. The survey was conducted in the two Indian states Uttar Pradesh and Bihar, in 2016 by Population Council under the guidance of the Ministry of Health and Family Welfare, Government of India. The UDAYA collected detailed information on family, media, community environment, assets acquired in adolescence, and quality of transitions to young adulthood indicators [39]. The sample size for Uttar Pradesh and Bihar was 10,350 and 10,350 adolescents aged 10-19 years, respectively. The required sample for each sub-group of adolescents was determined at 920 younger boys, 2350 older boys, 630 younger girls, 3750 older girls, and 2700 married girls in both states. The UDAYA adopted a multi-stage systematic sampling design to provide the estimates for states as a whole as well as for the urban and rural area of the states. The detailed information on the sampling procedure and survey design was published elsewhere [39]. The effective sample size for this study was 5969 adolescent boys aged $10-19$ years.

\section{Outcome variable}

The outcome variable was substance use among adolescent boys. The variable was recoded as 1 "yes" if the respondent is either consuming tobacco products or alcohol or drugs and was categorized as 0 "no" if the respondent does not consume any of the three products. The drug use was probed for the consumption of brown sugar (a heroin product), cocaine, and traditional cannabis-derivative products such as "ganja", "charas", and "bhang" [39].

\section{Predictor variables}

1. Substance use among family members was coded as "no" and "yes", i.e. if in a family anyone was consuming either tobacco products or alcohol or drugs were categorized as experiencing substance use "yes" otherwise "no," i.e. no one is consuming either of the three substances [40].

2. Age (in years) was coded as early adolescents (1014 years) and late adolescents (15-19 years) [40].

3. Current schooling was coded as never attended, dropout and currently attending [40].

4. Working status was coded as no and yes [40].

5. Media exposure was coded as no exposure, rare exposure and frequent exposure [40].

6. Caste was coded into Scheduled caste/Scheduled tribe (SC/ST) and non-SC/ST [41].

7. Religion was coded as Hindu and non-Hindu. The category of non-Hindu was recoded as the frequency of other religions except the Muslim religion was low [42].

8. Wealth index was coded as poorest, poorer, middle, richer and richest [43].

9. Residence was available in data as urban and rural [40].

10. States were recoded as Uttar Pradesh and Bihar [42].

\section{Community-level variables}

Community-level variables were constructed by aggregating the individual/household-level characteristics of the respondents to the primary sampling unit (PSU) level $[44,45]$. The UDAYA data provided a household wealth index (WI) based on information collected on household amenities and assets. The community economic index was divided into two categories, "high" and "low", with "low" being for PSUs whose average household WI was less than the national average of WI and "high" is for the remaining PSUs [44, 45]. Similarly, the individual's educational index was created based on the average years of schooling of women at the PSU level and similarly mother's educational index was also created [44]. The community-level substance use was also created based on average media exposure at the PSU level and then dividing it into low and high as per average substance use among the individuals in a particular community [45].

\section{Statistical analysis}

The study used univariate and bivariate analysis to show the sample distribution of the study population and the association between the outcome and predictor variables, respectively. Further, multilevel (three-level) logistic regression analysis [44] was used to assess the effects of the individual-, household-, and community-level variables on substance use among adolescent boys [45]. The random effects of household and community were estimated by using the melogit command in STATA (Version 15) [46].

The application of the multilevel modelling was justified by the hierarchal structure of the survey, where adolescents were nested within households and households were nested within primary sampling units (PSUs) [45]. First, a null model was run; that is, without keeping any explanatory variables [44]. This model represented the total variance in substance use at household and community levels [44]. In multivariate modelling, three models were fitted. In the first model, individual-level variables included, the second model included individual- and household-level variables. In the last model, community-level variables were added [45]. The fixed effects at the individual, household, and community levels, and the random effects at the household and community levels, were calculated [44, 45]. For all the estimated 
models, the significance of the fixed effect parameters was evaluated by using $p$-values $(p<0.05)[44,45]$. The mathematical description of the final model (three levels) is given below:

$$
\begin{aligned}
\operatorname{logit}\left(\pi_{i j k}\right)=\log \left(\frac{\pi_{i j k}}{1-\pi_{i j k}}\right)= & \beta_{0 j k}+\beta_{1} x_{1 i j k}+\beta_{2} x_{2 i j k} \\
& +\beta_{3} x_{3 i j k}+\ldots+\beta_{n} x_{n i j k}
\end{aligned}
$$

Here, $\pi_{i j k}=p\left(y_{i j k}=1\right)$ is the probability that adolescents (i) in the household j, from the PSU k, in the substance use. Where $y_{i j k}$ is equal to " 1 " if an adolescent boy uses substance use and "0" if they did not. The study defined this probability as a function of an intercept and the exploratory variables as follows: $\beta_{0 j k}=\beta_{0}+\mu_{0 j k}$.

In this equation, $\beta_{0 \mathrm{jk}}$ indicates that the paper modelled the intercept in this relationship as random at $j^{\text {th }}$ (household) and $k^{\text {th }}$ (PSU) levels. The variables $x_{1 i j k}$ to $x_{n i j k}$ were the explanatory variables, and their coefficients were the fixed effects. The technical advantage of this methodology relies on the error term structure. Linear or logistic regression models exhibit one error term for the whole equation, whereas multilevel analysis generates one error term for each level, allowing to isolate the individual-level and group-level residual variance. The split error term in the multilevel analysis allows assessing unobserved effects at every level [47].

\section{Results}

\section{Sample description}

Figure 1 depicts that about 15 and $5 \%$ of adolescent boys used tobacco and consumed alcohol, respectively. Moreover, nearly $16 \%$ of adolescent boys were using any substances (tobacco or alcohol or drug).

Figure 2 depicts that drug consumption among family members was the most important factor for adolescents to consume substance use. For instance, about $28 \%$ of adolescent boys consumed drugs, followed by alcohol (24.11\%) whose family members were consuming the same.

Socio-economic and demographic profiles of adolescent boys aged 10-19 years are presented in Table 1 . Nearly $65 \%$ of adolescent boys belonged to the late

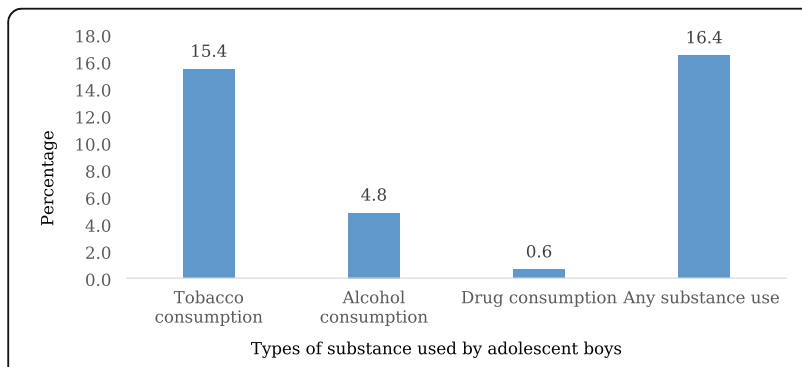

Fig. 1 Substance use among adolescent boys aged 10-19 years

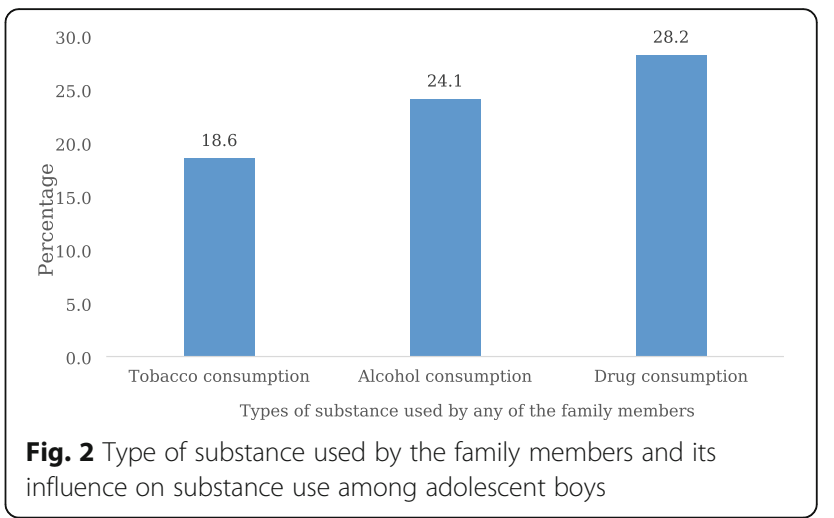

adolescent group, $18 \%$ of boys were school dropouts, and about $27 \%$ of adolescent boys were working. Nearly three-fourth of any family members of adolescent boys used any substances. Around three-fourth of adolescent boys had frequent media exposure and about a similar proportion of adolescents belonged to non-scheduled caste/scheduled tribe (SC/ST). About $31 \%$ of the community had low education, and $48 \%$ of the community belonged to the low wealth quintile.

\section{Prevalence of substance use among adolescent boys}

The percentage distribution of substance use among adolescent boys by background characteristics is shown in Table 2. The prevalence of substance use was significantly higher among late adolescents (22.9\%) compared to early ones (4.5\%). Adolescent boys who never attended school (38.5\%) or school dropout (40.3\%) had a higher prevalence of substance use, and it was lowest among those who were currently studying (10\%). Working boys (35.2\%) had a higher prevalence of substance use than not working ones (9.6\%). The prevalence of substance use was significantly higher among adolescents with no media exposure (20.3\%) compared to those who had frequent media exposure (16.4\%). It was found that substance use was more prevalent among boys (18.5\%) whose family members used any substances. Moreover, SC/ST (21.5\%) and non-Hindu (17.2\%) adolescent boys used more substances compared to their counterparts. The wealth of the family had a negative association with substance use among adolescent boys. The prevalence of substance use was significantly higher among boys (18.3\%) if the community had low education. Similarly, if the community belonged to the low wealth quintile, boys used more substances (17.7\%).

\section{Estimates from three-level random intercept model}

Estimates from multilevel logistic regression analysis for substance use among adolescent boys are presented in Table 3. Model 1 included individual-level explanatory 
Table 1 Socio-economic and demographic profile of adolescent boys aged 10-19 years

\begin{tabular}{lll}
\hline Background characteristics & Sample & Percentage \\
\hline Age (in years) & & \\
Early adolescents (10-14) & 2084 & 34.9 \\
Late adolescents (15-19) & 3885 & 65.1
\end{tabular}

\section{Current Schooling}

\section{Never attended \\ Dropout \\ Currently attending}

Working status

$$
\text { No }
$$

Yes

Substance use among family members

$$
\text { Someone in the family }
$$

Media exposure

$$
\begin{aligned}
& \text { No exposure } \\
& \text { Rarely } \\
& \text { Frequently }
\end{aligned}
$$

\section{Caste}

$$
\begin{aligned}
& \text { Scheduled Caste/Scheduled Tribe } \\
& \text { Non-Scheduled Caste/Scheduled Tribe }
\end{aligned}
$$

$\begin{array}{ll}190 & 3.2 \\ 1092 & 18.3 \\ 4687 & 78.5\end{array}$

\section{Religion}

Hindu

Non-Hindu

Wealth index

Poorest

Poorer

Middle

Richer

Richest

Community education

$$
\begin{aligned}
& \text { High } \\
& \text { Low }
\end{aligned}
$$

Community wealth

$$
\text { High }
$$

Community substance use

$$
\text { Low }
$$

\section{Residence}

$$
\begin{aligned}
& \text { Urban } \\
& \text { Rural }
\end{aligned}
$$

State

$$
\begin{aligned}
& \text { Uttar Pradesh } \\
& \text { Bihar }
\end{aligned}
$$$$
4069
$$$$
1900
$$

Table 2 Percentage distribution of substance use among adolescent boys by background characteristics

\begin{tabular}{ll}
\hline Background characteristics & Perce \\
\hline Age (in years) & \\
Early adolescents (10-14) & 4.5 \\
Late adolescents (15-19) & 22.9 \\
Current schooling & \\
Never attended & 38.5 \\
Dropout & 40.3 \\
Currently attending & 10.0
\end{tabular}

\section{Working status}

$$
\begin{aligned}
& \text { No } \\
& \text { Yes }
\end{aligned}
$$

Media exposure

No exposure

Rarely

frequently

Substance use among family members

No-one

Someone in the family

Caste

Scheduled Caste/Scheduled Tribe

Non- Scheduled Caste/Scheduled Tribe

\section{Religion}

Hindu

Non-Hindu

0.001

Wealth index

Poorest

Poorer

Middle

Richer

Richest

0.001

Community education

High

Low

0.048

Community wealth

High

Low

Community substance use

Low

High

Residence

Urban

Rural

\section{State}

$$
\begin{aligned}
& \text { Uttar Pradesh } \\
& \text { Bihar }
\end{aligned}
$$

Total 
Table 3 Multilevel logistic regression analysis assessing the effect of background characteristics on the likelihood of substance use among adolescent boys

\begin{tabular}{|c|c|c|c|}
\hline \multirow[t]{2}{*}{ Background characteristics } & Model-1 & Model-2 & Model-3 \\
\hline & OR $(95 \% \mathrm{Cl})$ & OR $(95 \% \mathrm{Cl})$ & OR $(95 \% \mathrm{Cl})$ \\
\hline \multicolumn{4}{|l|}{ Age (in years) } \\
\hline Early adolescents (10-14) & Ref. & Ref. & Ref. \\
\hline Late adolescents (15-19) & $7.38^{*}(1.67,32.6)$ & $6.81 *(3.07,15.07)$ & $6.65^{*}(3.06,14.45)$ \\
\hline \multicolumn{4}{|l|}{ Current schooling } \\
\hline Never attended & Ref. & Ref. & Ref. \\
\hline Dropout & $0.68(0.35,1.34)$ & $0.74(0.42,1.30)$ & $0.67(0.37,1.20)$ \\
\hline Currently attending & $0.08^{*}(0.01,0.59)$ & $0.11^{*}(0.04,0.32)$ & $0.10^{*}(0.03,0.29)$ \\
\hline \multicolumn{4}{|l|}{ Working status } \\
\hline No & Ref. & Ref. & Ref. \\
\hline Yes & $5.09^{*}(1.63,15.94)$ & $4.22 *(2.32,7.67)$ & $4.46^{*}(2.42,8.22)$ \\
\hline \multicolumn{4}{|l|}{ Media exposure } \\
\hline No exposure & Ref. & Ref. & Ref. \\
\hline Rarely & $0.88(0.44,1.74)$ & $0.92(0.49,1.73)$ & $0.89(0.47,1.68)$ \\
\hline frequently & $1.29(0.67,2.5)$ & $1.40(0.76,2.57)$ & $1.43(0.78,2.63)$ \\
\hline \multicolumn{4}{|l|}{ Substance use among family members } \\
\hline No-one & & Ref. & Ref. \\
\hline Someone in the family & & $2.22 *(1.48,3.33)$ & $2.13^{*}(1.44,3.17)$ \\
\hline \multicolumn{4}{|l|}{ Caste } \\
\hline Scheduled Caste/Scheduled Tribe & & Ref. & Ref. \\
\hline Non- Scheduled Caste/Scheduled Tribe & & $0.75(0.55,1.03)$ & $0.72 *(0.52,0.99)$ \\
\hline \multicolumn{4}{|l|}{ Religion } \\
\hline Hindu & & Ref. & Ref. \\
\hline Non-Hindu & & $1.09(0.77,1.55)$ & $1.28(0.88,1.84)$ \\
\hline \multicolumn{4}{|l|}{ Wealth index } \\
\hline Poorest & & Ref. & Ref. \\
\hline Poorer & & $0.69(0.42,1.15)$ & $0.72(0.44,1.19)$ \\
\hline Middle & & $0.80(0.50,1.30)$ & $0.90(0.56,1.45)$ \\
\hline Richer & & $0.66(0.40,1.08)$ & $0.78(0.47,1.28)$ \\
\hline Richest & & $0.80(0.49,1.33)$ & $1.05(0.62,1.78)$ \\
\hline \multicolumn{4}{|l|}{ Community education } \\
\hline High & & & Ref. \\
\hline Low & & & $0.78(0.56,1.09)$ \\
\hline \multicolumn{4}{|l|}{ Community wealth } \\
\hline High & & & Ref. \\
\hline Low & & & $1.31(0.90,1.92)$ \\
\hline \multicolumn{4}{|l|}{ Community substance use } \\
\hline Low & & & Ref. \\
\hline High & & & $1.24^{*}(1.01,1.68)$ \\
\hline \multicolumn{4}{|l|}{ Residence } \\
\hline Urban & & & Ref. \\
\hline Rural & & & $1.09(0.76,1.54)$ \\
\hline
\end{tabular}


Table 3 Multilevel logistic regression analysis assessing the effect of background characteristics on the likelihood of substance use among adolescent boys (Continued)

\begin{tabular}{|c|c|c|c|}
\hline \multirow[t]{2}{*}{ Background characteristics } & Model-1 & Model-2 & Model-3 \\
\hline & OR $(95 \% \mathrm{Cl})$ & OR $(95 \% \mathrm{Cl})$ & OR $(95 \% \mathrm{Cl})$ \\
\hline \multicolumn{4}{|l|}{ State } \\
\hline Uttar Pradesh & & & Ref. \\
\hline Bihar & & & $1.56^{*}(1.12,2.17)$ \\
\hline
\end{tabular}

variables such as the age of the adolescent boys, schooling, working status, and mass media exposure which all were significantly associated with substance use except media exposure. Model 2 included household-level variables in addition to the explanatory variables used in Model 1, and Model 3 added community-level predictors. Model 3 showed that late adolescents [OR: 6.65; CI: 3.06-14.45] had significantly higher odds of substance use than early ones. Boys who were currently studying [OR: 0.10; CI: 0.03-0.29] had 90\% fewer odds to use any substances compared to those who never attended school. The likelihood of substance use was 4.46 times significantly more likely among working boys [OR: 4.46; CI: 2.42-8.22] compared to not working ones. Similarly, the odds of substance use among boys whose family members used any substances [OR: 2.13; CI: 1.44-3.17] was 2.13 times higher compared to their counterparts. Further, we found that substance use was $24 \%$ [OR: 1.24; CI: 1.01-1.68] more likely among those adolescent boys who come from a community with high substance use in comparison to their counterparts who come from communities with low substance use.

A model applied without covariates (called the null model) on substance use among adolescent boys (Table 4) showed a significant amount of variation in the prevalence of substance use across families and communities. Based on the intra-class correlation coefficient (ICC) values, about $11 \%$ and $6 \%$ of the total variance in the prevalence of substance use were attributable to differences across families and communities, respectively. After including individual (Model 1), household (Model 2 ) and community-level variables (Model 3) in the null model, the ICC value decreased to $5 \%$ at the community level and increased to $56 \%$ at the household level.

\section{Discussion}

The present study uses the UDAYA survey to examine the association of substance use behavior by adolescent boys and their family members in Uttar Pradesh and Bihar. It was evident that the adolescent boys were higher likely to indulge in substance use if at least one of their family members also indulged in substance use. Further, substance use was common among those adolescent boys who have experienced high substance use in the community they come from. We also found a high degree of correlation in the propensity for substance use within the same household and the same community. These findings point towards the role played by constant environmental exposure to substance use within a household and in the surrounding community, which inculcates the habit of substance use among inquisitive adolescents.

Analyses revealed that adolescent boys of Uttar Pradesh and Bihar were more inclined towards tobacco consumption behavior. Thus, the behavior not only questions the different tobacco policies introduced in India but shows the ill effect of the easy availability and inexpensive nature of such products among Indian adolescents [10, 34]. Moreover, drug consumption among adolescent boys was only $0.6 \%$, but its consumption among their family members seems to be the substance that is more influential for them. Further, the association of adolescent boys substance use with their family was consistent with a study from India which had also revealed that in familial settings, if parents, grandparents, or elder siblings frequently ask the adolescent boys of the family to fetch tobacco-based substances or alcohol, then the boy indulges in early usage of such substances [13]. Moreover, adolescents may perceive this behavior

Table 4 Variance estimates across families and communities, and the intra-class correlation coefficient for the multilevel models for substance use among adolescent boys

\begin{tabular}{lllll}
\hline Random Effect Parameters & Null & Model 1 & Model 2 & Model 3 \\
\hline Community (PSU) random variance (SE) & $0.20(0.06)$ & $0.57(0.39)$ & $0.40(0.20)$ & $0.35(0.17)$ \\
Household random variance (SE) & $0.18(0.39)$ & $5.09(6.32)$ & $3.83(2.83)$ & $3.78(2.76)$ \\
Community (PSU) ICC (\%) & 5.7 & 6.0 & 5.4 & 4.7 \\
Household ICC (\%) & 10.7 & 63.1 & 56.3 & 55.6 \\
\hline
\end{tabular}


as a tradition after watching their elders. However, it is often found in Indian tradition that younger individuals are not expected to use such substances in front of their elders; this restriction can also create the curiosity to try different substances secretly among adolescents.

Indeed, family members' consumption behavior was predictive of adolescent's substance use habits. Multilevel analyses revealed the importance of the environment in which an adolescent resides, which was consistent with the findings of previous research [33]. The role of family and community cannot be denied and was found to be influential as the risk of substance use is more likely among adolescent boys belonging to the same household of the same community. It should be noted that households and communities can have both pros and cons on adolescent's behavior. Although the present study found that individuals sharing the same characteristics in certain households and communities paving the way for substance use among adolescent boys. But introducing community-driven programs can also help in curbing such behavior among adolescent boys. Moreover, sensitization of family members can further help in the reduction of substance use behavior of adolescent boys. Evidence of higher adolescent substance use is observed among the working population, which is consistent with an Indian study [48]. The present study shows boys in the late adolescence period are more prone to substance use. Such association brought forward the role of providing knowledge about harmful effects of substance use among adolescent right from the early phase, so that they may not get indulge in such behavior later or while their peer exposure during work. A higher level of formal education among adolescents had an influential role in keeping them away from different substance use, indicating the role of education in an adolescent's life. The adolescent boys who were attending school were less likely to use any substance, and this finding was consistent with an existing Indian study [13]. Another study from high school Indian adolescents had a consistent finding with this study which shows that media can increase substance use behavior by providing a frequent source of provoking advertisements [49]. However, the results were contradicted with a study that shows both pro and anti-effect of media on humans health [50]. These individual factors have also detrimental effects when seen in the family and community context.

Using data from the two Indian states (i.e., Uttar Pradesh and Bihar), this study had tried to fill the knowledge gaps from these states about the determinants of substance use among adolescent boys. Present study utilizes the data available on familial and community contexts in Uttar Pradesh and Bihar which are often limited in other surveys. Moreover, the survey gathered information from adolescent boys regarding their usage of different substances like tobacco-, drugs- and alcohol-based products. Unlike in other Indian surveys, this helped us not to stick to any particular consumption behavior. Existing literature showing the effect of the family-level risk factors is mostly based on the developed countries [31-33]. Only a few existing studies from India had talked about the effect of the family members' consumption behavior on adolescents of the family. However, our study has examined the effect of both family-level and community-level factors and provided clear evidence of substance use risk among adolescent boys belonging to the same household of the same community. The results of this study are backed by few studies of developed and developing countries and expand our knowledge towards adolescent substance use.

However, it is also important to consider a few limitations of this study. This study did not consider important school- and peer-related characteristics of adolescents like academic performance, indulged in a bad peer group, faces violence, or bullying. One study had found evidence of academic performance and peer influence with adolescent substance use [51]. Also, a longitudinal or panel data study is required to notice the behavior of adolescents at later ages. Nested associations should also be noticed in different ages and regions. Moreover, confined to data of Uttar Pradesh and Bihar, these results cannot be generalized to that of the whole nation. However, it does provide interesting insights into the substance use pattern of adolescent boys from the two high-prevalence Indian states.

\section{Conclusion}

Despite some limitations, this study highlights the relevance of family risk factors on adolescent boy's substance use behavior. Moreover, the study shows that among $16 \%$ of adolescent boys indulged in substance use behavior, tobacco consumption (15.4\%) had increased at an alarming rate. Community substance use among family members had also emerged as an important indicator of the growing adolescent boy's substance use behavior. Our findings reemphasize the need to bring the children for schooling education and target those adolescents who were unable to continue their education and are forced to work for livelihood in early and late adolescence period. Further, the evidence, of substance use is more common among adolescent boys belonging to the same household of the same community, provided additional support to this study and turned the attention towards targeting these factors. The study had highlighted the need for interventions, which target the adolescent boys right from their household. 


\section{Abbreviations}

OR: Odds Ratio; Cl: Confidence Interval; UDAYA: Understanding the Lives of Adolescents and Young Adults; SC: Scheduled Caste; ST: Scheduled Tribe

\section{Acknowledgments}

This paper was written using data collected as part of Population Council's UDAYA study, funded by the Bill and Melinda Gates Foundation and the David and Lucile Packard Foundation. No additional funds were received for the preparation of the paper. The funders had no role in study design, data collection, analysis, decision to publish or preparation of the manuscript.

\section{Authors' contributions}

Conceptualization, SS and PK.; Methodology, RP, SS and PK; Formal Analysis, SS.; Writing - Original Draft Preparation, RR and RP; Writing - Review \& Editing, RR and RP; Visualization, PD, SS and PK; Supervision, PD. The authors read and approved the final manuscript.

\section{Funding}

No funds were received for the preparation of the paper

\section{Availability of data and materials}

Data was collected as part of Population Council's UDAYA study which is publicly available on the site of Harvard Dataverse at https://dataverse. harvard.edu/dataset.xhtml?persistentld=doi:10.7910/DVN/RRXQNT

\section{Declarations}

Ethics approval and consent to participate

Informed consent was obtained from all subjects at the time of the survey.

\section{Consent for publication}

Not Applicable.

\section{Competing interests}

The authors declare no competing interest.

Received: 15 March 2021 Accepted: 1 October 2021

Published online: 20 October 2021

\section{References}

1. Eccles JS, Midgley C, Wigfield A, Buchanan CM, Reuman D, Flanagan C, et al. Development during adolescence: The impact of stage-environment fit on young adolescents' experiences in schools and in families (1993). In: The evolution of psychology: Fifty years of the American Psychologist. Washington, DC American Psychological Association; 1997. p. 475-501.

2. Bor W, Dean AJ, Najman J, Hayatbakhsh R. Are child and adolescent mental health problems increasing in the 21st century? A systematic review. Aust New Zeal J Psychiatry. 2014;48(7):606-16. https://doi.org/10.1177/0004 867414533834

3. Degenhardt L, Whiteford HA, Ferrari AJ, Baxter AJ, Charlson FJ, Hall WD, et al. Global burden of disease attributable to illicit drug use and dependence: findings from the global burden of disease study 2010 Lancet. 2013;382(9904):1564-74. https://doi.org/10.1016/S0140-6736(13)61 530-5.

4. Gore FM, Bloem PJN, Patton GC, Ferguson J, Joseph V, Coffey C, et al. Global burden of disease in young people aged 10-24 years: a systematic analysis. Lancet. 2011;377(9783):2093-102. https://doi.org/10.1016/S0140-673 6(11)60512-6.

5. Segal BM, Stewart JC. Substance use and abuse in adolescence: an overview. Child Psychiatry Hum Dev. 1996;26(4):193-210. https://doi.org/10.1 007/BF02353237.

6. WHO. Harmful use of alcohol kills more than 3 million people each year, most of them men, vol. 2; 2018. p. 2019

7. Menon GR, Singh L, Sharma P, Yadav P, Sharma S, Kalaskar S, et al. National burden estimates of healthy life lost in India, 2017: an analysis using direct mortality data and indirect disability data. Lancet Glob Health. 2019;7(12): e1675-84. https://doi.org/10.1016/S2214-109X(19)30451-6.

8. Ambekar A, Agrawal A, Rao R, Mishra AK, Khandelwal SK, Chadda R. Magnitude of substance use in India. New Delhi: Ministry of Social Justice and Empowerment, Government of India; 2019.
9. Tripathi BM, Lal R. Substance abuse in children and adolescents. Indian J Pediatr. 1999;66(4):569-75. https://doi.org/10.1007/BF02727172.

10. Gupta PC, Ray CS. Smokeless tobacco and health in India and South Asia. Respirology. 2003;8(4):419-31. https://doi.org/10.1046/j.1440-1843.2003. 00507.x.

11. Jiloha RC. Prevention, early intervention, and harm reduction of substance use in adolescents. Indian J Psychiatry. 2017;59(1):111-8. https://doi.org/1 0.4103/0019-5545.204444.

12. Merline AC, O'Malley PM, Schulenberg JE, et al. Substance use among adults 35 years of age: prevalence, adulthood predictors, and impact of adolescent substance use. Am J Public Health. 2004;94(1):96-102. https://doi.org/10.21 05/ajph.94.1.96.

13. Chadda RK, Sengupta SN. Tobacco use by Indian adolescents. Tob Induc Dis. 2002;1:111.

14. Gibbs A, Jewkes R, Willan S, Washington L. Associations between poverty, mental health and substance use, gender power, and intimate partner violence amongst young (18-30) women and men in urban informal settlements in South Africa: a cross-sectional study and structural equation model. PLoS One. 2018;13(10):e0204956. https://doi.org/10.1371/journal. pone.0204956.

15. Kanamori M, Shrader C-H, St. George S, Adkins T, Bartholomew TS, Sanchez $M$, et al. Influences of immigration stress and occupational exploitation on Latina seasonal workers' substance use networks: a qualitative study. J Ethn Subst Abus. 2020:1-19. https://doi.org/10.1080/15332640.2020.1778591.

16. Barkin SL, Smith KS, DuRant RH. Social skills and attitudes associated with substance use behaviors among young adolescents. J Adolesc Health. 2002; 30(6):448-54. https://doi.org/10.1016/S1054-139X(01)00405-0.

17. Wu L-T, Schlenger W, Galvin D. The relationship between employment and substance use among students aged 12 to 17. J Adolesc Health. 2003:32(1): 5-15. https://doi.org/10.1016/S1054-139X(02)00447-0.

18. Saluja BS, Grover S, Irpati AS, Mattoo SK, Basu D. Drug dependence in adolescents 1978-2003: a clinical-based observation from North India. Indian J Pediatr. 2007;74(5):455-8. https://doi.org/10.1007/s12098-007$0077-z$

19. Saikia N, Debbarma B. The socioeconomic correlates of substance use among male adults in Northeast India. Clin Epidemiol Glob Health. 2020; 8(1):149-57. https://doi.org/10.1016/j.cegh.2019.06.004.

20. Leonardi-Bee J, Jere ML, Britton J. Exposure to parental and sibling smoking and the risk of smoking uptake in childhood and adolescence: a systematic review and meta-analysis. Thorax. 2011;66(10):847-55. https://doi.org/10.113 6/thx.2010.153379.

21. Lynskey MT, Fergusson DM, Horwood L. The effect of parental alcohol problems on rates of adolescent psychiatric disorders. Addiction. 1994; 89(10):1277-86. https://doi.org/10.1111/j.1360-0443.1994.tb03306.x.

22. Fawzy Fl, Coombs RH, Simon JM, Bowman-Terrell M. Family composition, socioeconomic status, and adolescent substance use. Addict Behav. 1987; 12(1):79-83. https://doi.org/10.1016/0306-4603(87)90013-X.

23. Johnson GM, Shontz FC, Locke TP. Relationships between adolescent drug use and parental drug behaviors. Adolescence. 1984:19(74):295-9.

24. Fawzy Fl, Coombs RH, Gerber B. Generational continuity in the use of substances: the impact of parental substance use on adolescent substance use. Addict Behav. 1983;8(2):109-14. https://doi.org/10.1016/0306-4603(83 )90003-5.

25. Li C, Pentz MA, Chou C. Parental substance use as a modifier of adolescent substance use risk. Addiction. 2002:97(12):1537-50, https://doi.org/10.1046/ j.1360-0443.2002.00238.x

26. Wallace LN. Sibling popularity: a moderator of sibling influence for adolescent substance use. Addict Res Theory. 2015;23(6):481-9. https://doi. org/10.3109/16066359.2015.1036046.

27. Lonczak HS, Fernandez A, Austin L, Marlatt GA, Donovan DM. Family structure and substance use among American Indian youth: a preliminary study. Fam Syst Health. 2007;25(1):10-22. https://doi.org/10.1037/1091-752 7.25.1.10.

28. Dandona L, Dandona R, Kumar GA, Shukla DK, Paul VK, Balakrishnan K, et al. Nations within a nation: variations in epidemiological transition across the states of India, 1990-2016 in the global burden of disease study. Lancet. 2017;390(10111):2437-60. https://doi.org/10.1016/S01406736(17)32804-0

29. Tsering D, Pal R, Dasgupta A. Substance use among adolescent high school students in India: a survey of knowledge, attitude, and opinion. J Pharm Bioallied Sci. 2010;2(2):137. https://doi.org/10.4103/0975-7406.67005. 
30. Kapoor SK, Anand K, Kumar G. Prevalence of tobacco use among school and college going adolescents of Haryana. Indian J Pediatr. 1995;62(4):4616. https://doi.org/10.1007/BF02755068.

31. Hawkins JD, Van Horn ML, Arthur MW. Community variation in risk and protective factors and substance use outcomes. Prev Sci. 2004;5(4):213-20. https://doi.org/10.1023/B:PREV.0000045355.53137.45.

32. Pettit GS, Bates JE, Dodge KA, Meece DW. The impact of after-school peer contact on early adolescent externalizing problems is moderated by parental monitoring, perceived neighborhood safety, and prior adjustment. Child Dev. 1999;70(3):768-78. https://doi.org/10.1111/1467-8624.00055.

33. Mayberry ML, Espelage DL, Koenig B. Multilevel modeling of direct effects and interactions of peers, parents, school, and community influences on adolescent substance use. J Youth Adolesc. 2009;38(8):1038-49. https://doi. org/10.1007/s10964-009-9425-9.

34. Ladusingh L, Singh A. Contextual correlates of intensity of smoking in Northeast India. Int J Public Health. 2015;60(3):317-26. https://doi.org/10.1 007/s00038-015-0652-4.

35. Davey S, Raghav SK, Davey A, Singh J. Perceptions regarding tobacco usage among adolescents \& young adults in a district of Western Uttar Pradesh (India): a qualitative study. Int J Community Med Public Health. 2015;2(2):94. https://doi.org/10.5455/2394-6040.ijcmph20150505.

36. Rawat R, Gouda J, Shekhar C. Smokeless tobacco use among adult males in India and selected states: assessment of education and occupation linkages. J Hum Behav Soc Environ. 2016;26(2):236-46. https://doi.org/10.1080/109113 59.2015.1083507.

37. Singh A, Arora M, Bentley R, Spittal MJ, Do LG, Grills N, et al. Geographic variation in tobacco use in India: a population-based multilevel crosssectional study. BMJ Open. 2020;10(6):e033178. https://doi.org/10.1136/ bmjopen-2019-033178.

38. Tikoo VK, Dhawan A, Pattanayak RD, et al. Assessment of pattern and profile of substance use among children in India. In: Natl Comm Prot Child Rights by Natl Drug Depend Treat Cent [NDDTC]. New Delhi: All India Inst Med Sci [AllMS]; 2013.

39. Population Council. UDAYA, adolescent survey, Bihar and Uttar Pradesh, 2015-16; 2017. https://doi.org/10.7910/DVN/RRXQNT.

40. Chauhan S, Srivastava S, Kumar $P$, et al. Interaction of substance use with physical activity and its effect on depressive symptoms among adolescents. J Subst Use. 2020;3:1-7.

41. Srivastava S, Kumar S. Does socio-economic inequality exist in micronutrients supplementation among children aged 6-59 months in India? Evid Nat Fam Health. 2021;21(1):1-12. https://doi.org/10.1186/s12889-021-1 0601-6.

42. Kumar P, Srivastava S, Mishra PS, Sinha D, Dhillon P. Does depressive symptoms, physical inactivity and substance use catalyze the suicidal tendency among adolescents? Evidence from a cross-sectional study. Child Youth Serv Rev. 2020;119:105661. https://doi.org/10.1016/j.childyouth.2020.1 05661.

43. Singh SK, Srivastava S, Chauhan S. Inequality in child undernutrition among urban population in India: a decomposition analysis. BMC Public Health. 2020;20(1):1852. https://doi.org/10.1186/s12889-020-09864-2.

44. Kumar $\mathrm{P}$, Sonekar $\mathrm{H}$, Banerjee $\mathrm{A}$, et al. A multilevel analysis of factors associated with malnutrition among tribal children in India: Evidence from National Family Health Survey 2015-16. Child Indic Res. 2021. https://doi. org/10.1007/s12187-021-09812-5.

45. Kumar P, Dhillon P. Household-and community-level determinants of lowrisk caesarean deliveries among women in India. J Biosoc Sci. 2021;53(1):5570. https://doi.org/10.1017/S0021932020000024.

46. StataCorp. Stata Statistical Software: Release 15. College Station: StataCorp LLC; 2017.

47. Kumar P, Dhillon P. Household-and community-level determinants of lowrisk caesarean deliveries among women in India. J Biosoc Sci. 2020;53(1):116. https://doi.org/10.1017/S0021932020000024.

48. Agrawal S. Analyzing Adolescent Risk-Taking Behavior in India: Findings from a large-scale survey. France: IUSSP XXV International Population Conference; 2005. p. 18-23.

49. Tsering D, Pal R, Dasgupta A. Licit and illicit substance use by adolescent students in eastern India: prevalence and associated risk factors. J Neurosci Rural Pract. 2010;1(02):76-081. https://doi.org/10.4103/0976-3147.71721.

50. Wakefield M, Flay B, Nichter M, Giovino G. Role of the media in influencing trajectories of youth smoking. Addiction. 2003;98:79-103. https://doi.org/1 0.1046/j.1360-0443.98.s1.6.x
51. Branstetter SA, Low S, Furman W. The influence of parents and friends on adolescent substance use: a multidimensional approach. J Subst Use. 2011; 16(2):150-60. https://doi.org/10.3109/14659891.2010.519421.

\section{Publisher's Note}

Springer Nature remains neutral with regard to jurisdictional claims in published maps and institutional affiliations.
Ready to submit your research? Choose BMC and benefit from:

- fast, convenient online submission

- thorough peer review by experienced researchers in your field

- rapid publication on acceptance

- support for research data, including large and complex data types

- gold Open Access which fosters wider collaboration and increased citations

- maximum visibility for your research: over $100 \mathrm{M}$ website views per year

At BMC, research is always in progress.

Learn more biomedcentral.com/submissions 